\title{
nESARECH S SOOH PHVSICA
}

Origem, composição, processos de recolha e conservação da saliva para análise de biomarcadores relevantes no controle da resposta ao exercício

\section{Autor(es): $\quad$ Lopes, Renata Fiedler; Rama, Luis Manuel Pinto Lopes; Teixeira, Ana Maria Miranda Botelho}

Publicado por: Imprensa da Universidade de Coimbra

URL

persistente:

URI:http://hdl.handle.net/10316.2/38213

DOI:

DOI:http://dx.doi.org/10.14195/2182-7087_6_3

Accessed : $\quad$ 26-Apr-2023 10:09:55

A navegação consulta e descarregamento dos títulos inseridos nas Bibliotecas Digitais UC Digitalis, UC Pombalina e UC Impactum, pressupõem a aceitação plena e sem reservas dos Termos e Condições de Uso destas Bibliotecas Digitais, disponíveis em https://digitalis.uc.pt/pt-pt/termos.

Conforme exposto nos referidos Termos e Condições de Uso, o descarregamento de títulos de acesso restrito requer uma licença válida de autorização devendo o utilizador aceder ao(s) documento(s) a partir de um endereço de IP da instituição detentora da supramencionada licença.

Ao utilizador é apenas permitido o descarregamento para uso pessoal, pelo que o emprego do(s) título(s) descarregado(s) para outro fim, designadamente comercial, carece de autorização do respetivo autor ou editor da obra.

Na medida em que todas as obras da UC Digitalis se encontram protegidas pelo Código do Direito de Autor e Direitos Conexos e demais legislação aplicável, toda a cópia, parcial ou total, deste documento, nos casos em que é legalmente admitida, deverá conter ou fazer-se acompanhar por este aviso. 

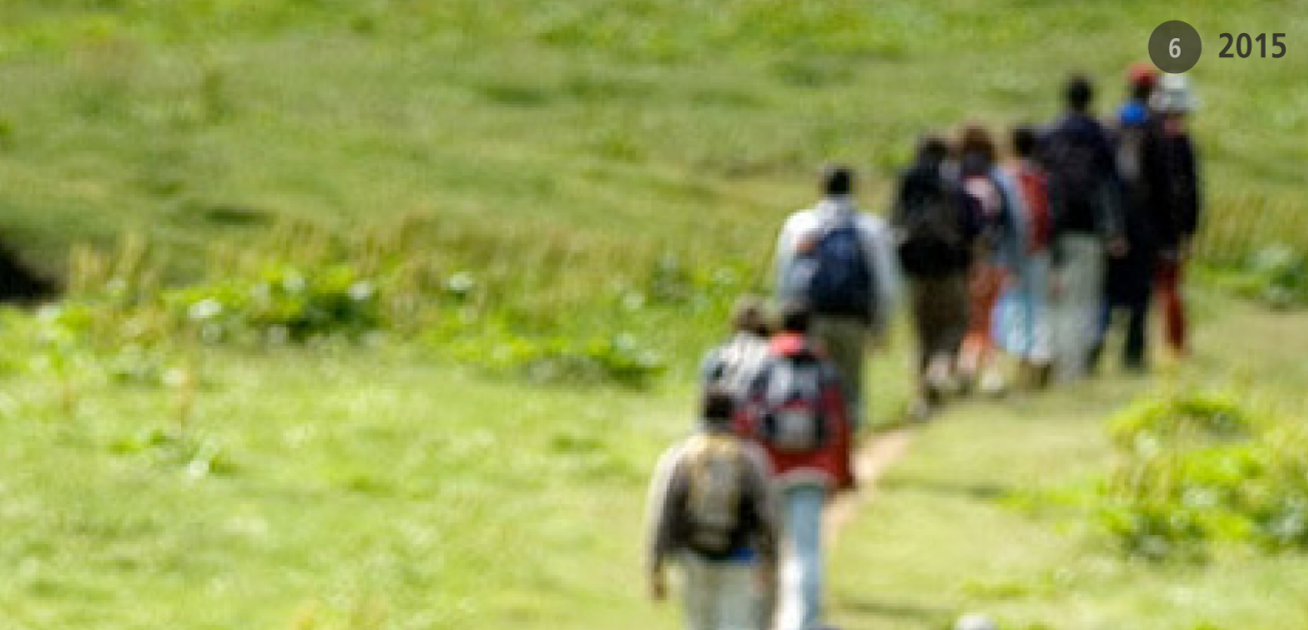
2・ IMUNOLOGIA DO DESPORTO / SPORT IMMUNOLOGY

ORIGEM, COMPOSIÇÃO, PROCESSOS DE RECOLHA E CONSERVAÇÃO DA SALIVA PARA ANÁLISE DE BIOMARCADORES RELEVANTES NO CONTROLE DA RESPOSTA AO EXERCICIO / ESSENTIAL CONCEPTS ON USING SALIVERY BIOMARKERS TO MONITORIZE THE EXERCISE IMPACT 

Renata Fiedler Lopes', Luis Manuel Pinto Lopes Rama', Ana Maria Miranda Botelho Teixeira $^{1}$

Correspondência: Renata Fiedler Lopes, R. Arcésio Correia Lima, 852 casa 2. Atuba. Curitiba. Paraná. Brasil. CEP 82630130; ou Faculdade de Ciências do Desporto e Educação Física, Estádio Universitário de Coimbra, Pavilhão III, 3040-156 Coimbra, Portugal. Contacto: +55 (41) 96445747 / + 55 (41)32035788

E-mail: refiedlerlopes@gmail.com

luisrama@fcdef.uc.pt; ateixeira@fcdef.uc.pt

\section{RESUMO}

O objetivo deste estudo é o de referenciar de forma sistemática e didáctica a informação relevante publicada em jornais internacionais nos últimos 10 anos relativa à composição salivar, métodos e procedimentos de recolha e armazenagem de saliva e a utilização de biomarcadores salivares em pesquisas relacionadas com a resposta e o impacto do exercício sobre estes parâmetros biológicos. Neste sentido, após a análise de trabalhos de revisão sistemática previamente realizados, percebeu-se a inexistência de uma revisão sistemática sobre o assunto na língua portuguesa e inglesa. A partir da exclusão do termo "systematic" (sistemática), foram encontrados na base de dados B-ON, 108 publicações; no PUBMED 8 resultados, LILACS, 4 resultados, e SCIELO não apresentou nenhum artigo de revisão com o descritor supracitado. Após excluídos: (1) artigos que utilizavam amostras animais e/ou plantas (2) artigos focados em aspectos de doenças ou síndromes, (3) artigos que utilizassem qualquer tipo de intervenção (uso de alimentos ou suplementos para posterior análise da saliva), (4) artigos repetidos em diferentes bases de dados, 17 artigos foram selecionados para serem lidos integralmente, e somente 11 inferiam no assunto específico sobre a origem e composição da saliva, métodos de recolha, processamento e análise de biomarcadores salivares.

PALAVRAS-CHAVE: saliva, biomarcadores salivares, revisão sistemática

\footnotetext{
1 Faculdade de Ciências do Desporto e Educação Física, Universidade de Coimbra - Coimbra - Portugal.
} 


\begin{abstract}
The purpose of this study was to be a didactic reference in systematic reviews about salivary composition, the physiology of saliva, the data collection and storage devices and the utilization of salivary biomarkers in sport and exercise researches. No article in the literature was found with these pre requisites, in Portuguese or English language. The term "systematic" was deleted and finally, we have found in data basis B-ON, 108 results, in PUBMED, 8 results, LILACS, 4 results and SCIELO not submitted any review paper with the description above. They were excluded: (1) articles with animals or plants samples, (2) articles focused in syndromes, disabilities or diseases, (3) articles with intervention process to posterior analyses of saliva (like supplementation or feeding), (4) same article at different data basis. Only 17 articles were selected to be read integrally, and just 11 were pertinent of this review, focused in origin and saliva composition, data collection and processing and salivary biomarkers.
\end{abstract}

KEYWORDS: saliva, salivary biomarkers, systematic review 


\section{INTRODUÇÃO}

O interesse na saliva tem atraído muitos pesquisadores nas últimas décadas como uma ferramenta útil e confiável para diagnosticar, entre outros, doenças hereditárias, doenças autoimunes, doenças orais, riscos cardiovasculares, câncer, alterações hormonais e, atualmente, na área do treinamento, monitorar os níveis de intensidade do treino, estresse, diminuição no sistema imunológico dos atletas, e evitar estados de "overtraining" e/ou "overreaching" durante temporadas de competição.

A saliva tem mostrado ser uma alternativa interessante à utilização de sangue, plasma, soro ou urina para diagnósticos, principalmente devido à sua natureza não invasiva, indolor, fácil recolha e baixo custo. Além destas vantagens, pode ser usada em populações especiais onde as coletas sanguíneas são dificultadas como no caso de estudos com crianças e adolescentes, por sua composição apresentar menor concentração de sal quando comparada a urina, e por poderem ser analisadas mais de 3000 proteínas em uma simples amostra (Amado, Ferreira e Vitorino, 2013).

Apesar das recolhas serem de fácil acesso, variáveis como idade, gênero, dieta, ritmo circadiano e variabilidade interindividual devem ser tidas em consideração. O processo padrão de coleta e processamento da saliva deve respeitar os seguintes aspectos: recolhas no mesmo horário do dia para reduzir o efeito circadiano de alguns parâmetros, assegurar no mínimo 2 horas após uma grande refeição, a boca deve ter sido previamente lavada, mas sem uso de pasta dental ou enxaguantes bucais, refrigeração logo após a recolha e congelamento a temperatura mínima de $-20^{\circ} \mathrm{C}$ até posterior análise.

Este é um artigo didático para o meio acadêmico e futuros investigadores que pretendam aprofundar o conhecimento de marcadores salivares, em estudos como os que visam o controlo da carga de treino e avaliações desportivas.

Iniciaremos a revisão com os aspectos anatômicos, fisiológicos e procedimentos de re-

colha e controlo de variáveis que podem vir a condicionar a fidedignidade dos resultados. Para tal fim, utilizamos o método sistemático de procura de artigos em bases de dados científicas nos últimos 10 anos, em português e inglês.

\section{Anatomia das Glândulas Salivares}

Do ponto de vista anatômico, as glândulas salivares dividem-se em maiores (parótida, submandibular, sublingual) e menores. As glândulas salivares são estruturas túbulo-alveolares que contém pontos secretórios: ácinos, um sistema tubular e ductos excretores. Durante essa passagem a concentração de vários eletrólitos muda devido ao transporte iônico ativo, o que rende ao fluído oral sua característica hipotônica quando comparado ao plasma. Cada glândula possui ducto secretor próprio que se abre na cavidade oral. Estes ductos são referenciados como intercalados, estriados e ductos excretores. A região acinar 
é o sítio de formação primária dos fluídos, eletrólitos e da maior parte da secreção protéica glandular (Aps e Martens, 2005).

A saliva é secretada por três grandes pares de glândulas salivares (submaxilares, parótidas e sublingual) e mais de 600 menores glândulas mucosais que também estão presentes na cavidade oral (Papacosta \& Nassis, 2011).

\section{Glândula Parótida}

A parótida é a principal e a maior das glândulas salivares. Ela pesa entre 14 e $28 \mathrm{~g}$, e localiza-se abaixo do crânio e, posterior ao ramo da mandíbula, apresentando forma de prisma quadrangular. Seu ducto secretor (Stensen, ou no Latim Stenon) desemboca na boca ao nível do colo do $1^{\circ}$ molar superior. A parótida recebe o seu suprimento sanguíneo dos ramos da artéria carótida externa. A enervação parassimpática da glândula provém majoritariamente do nervo glossofaríngio (IX par craniano) enquanto que a enervação simpática é proveniente de fibras pós-ganglionares do gânglio cervical superior (Farnaud et al, 2010). A parótida, quanto à forma da porção secretora e ramificação do canal excretor, representa um exemplo de glândula acinar composta, essencialmente serosa, e a sua atividade representa cerca de $23 \%$ da saliva encontrada na cavidade oral (Papacosta \& Nassis, 2011).

\section{Glândula Submandibular}

A glândula submandibular, pesa de 10 a 15g, e encontra-se em um sítio delimitado externamente pela mandíbula, superiormente por musculatura do soalho da boca e inferiormente pela fáscia cervical superficial. Seu ducto secretor (Wharton) passa entre os músculos milo-hióide e hioglosso, sendo cruzado pelo XII par craniano e a veia lingual superficial. A glândula submandibular recebe o seu suprimento sanguíneo das artérias faciais e linguais. A enervação parassimpática provém do nervo facial (VII par craniano), alcançando a glândula através do nervo lingual e gânglio submandibular (Farnaud et al, 2010). O sistema apresenta uma organização semelhante ao da parótida, sendo os canais estriados mais longos e, portanto mais numerosos à observação em cortes histológicos, enquanto que os canais intercalares são curtos. Os ácinos são do tipo seroso, mucoso e alguns deles mistos (com um componente celular mucoso e outro seroso). Considerando a forma da porção secretora e a disposição do sistema excretor, a glândula submandibular é classificada com uma glândula túbulo-acinar composta e é-lhe atribuída a produção de cerca de $65 \%$ da saliva encontrada na cavidade oral (Papacosta \& Nassis, 2011). 


\section{Glândula Sublingual}

A glândula sublingual localiza-se paralelamente ao corpo do maxilar, e pesa somente 2g. Encontra-se posterior ao ramo da mandíbula, abaixo da mucosa bucal e acima do milo-hióide. Possui vários ductos de drenagem, sendo o maior deles chamado de ducto de Rivinus. A glândula sublingual recebe o seu suprimento sanguíneo da artéria sublingual e submentoniana. O nervo facial (VII par craniano), o nervo lingual e gânglio submandibular providenciam a inervação parassimpática (Farnaud et al, 2010). A secreção é de natureza mucosa, sendo a glândula classificada como túbulo-acinar composta. Os canais intercalares são muito pequenos, razão pela qual é rara a sua observação em cortes histológicos, o mesmo se verificando relativamente aos canais estriados. A glândula sublingual é responsável pela produção de $4 \%$ da saliva presente na cavidade oral (Papacosta \& Nassis, 2011).

As glândulas salivares menores são estimadas entre 600 a 1000 pequenas glândulas independentes, encontrando-se em toda a membrana oral da mucosa bucal, labial, palatal distal e lingual, e que secretam aproximadamente $8 \%$ da saliva total (Papacosta \& Nassis, 2011; Eliasson e Carlen, 2010, Schipper et al, 2007).

\section{Fisiologia da saliva}

As principais funções da saliva são: a digestão, proteção, lubrificação, ação de limpeza, manutenção da integridade dental e percepção do sabor (Deepa e Thirrunsvukkarasu, 2010)

A saliva contem dois tipos principais de secreção protéica: a secreção serosa, contendo alfa-amilase ou ptialina - enzima que faz a digestão dos amidos, e a secreção mucosa, contendo mucina para a lubrificação e proteção das superfícies. Nos humanos, as glândulas parótidas são genuinamente compostas por células serosas, enquanto as glândulas submaxilares são mistas: compostas por células mucosas e serosas, e as sublinguais são compostas somente por células mucosas (Deepa e Thirrunsvukkarasu, 2010; Aps e Martens, 2005).

As glândulas salivares são órgãos efetores, que em resposta a estímulos neurais produzem uma grande quantidade de fluídos e eletrólitos para fora do organismo. O volume de saliva translocada por dia através das glândulas salivares aproxima-se de $20 \%$ do total do volume plasmático (aproximadamente $750 \mathrm{ml}$ ) (Papacosta e Nassis, 2011), no entanto, esse volume mostra não ser influenciado pelo momento do dia, mas pelo tipo de estímulo de salivação. Estímulos olfatórios e fome, dor, alterações hormonais relacionados à gravidez ou menopausa, medicamentos de estímulo simpático, parassimpático, anti-adrenérgico e anti-colinérgico podem alterar o fluxo salivar normal (Aps e Martens, 2005). 


\section{Fluxo salivar}

Quando se procedem a análises do conteúdo salivar de algumas proteínas, é necessário considerar o fluxo salivar que poderá constituir um fator determinante na eficácia de alguns processos imunes e condicionar a interpretação dos valores medidos.

Em condições de repouso, indivíduos saudáveis secretam, sem estimulação, uma taxa aproximada de 0,3 a 0,65 mililitros de saliva por minuto (Papacosta e Nassis, 2011; Aps \& Martens, 2005). Uma média de 0,5 mililitros de saliva a cada minuto, quase totalmente do tipo mucoso. O maior volume de saliva é produzido antes, durante e após as refeições, alcançando seu pico máximo próximo ao meio dia, e caindo consideravelmente a noite, durante o sono (Deepa e Thirrunsvukkarasu, 2010).

O exercício físico faz a ativação do sistema nervoso simpático, e espera-se que o exercício vigoroso de alta intensidade, reduza a taxa de fluxo salivar e modifique seus componentes. A desidratação, hiperventilação, o uso de medicamentos, fumo e álcool, o estado nutricional, jejum e doenças sistêmicas, também podem ser fatores que influenciam essa diminuição do fluxo salivar (De Almeida et al, 2008).

Alguns estudos sugerem que a taxa de fluxo salivar é influenciada pela idade, tendo pessoas idosas com menores taxas de fluxo salivar não-estimulada comparadas a indivíduos mais jovens (De Almeida et al, 2008; Dodds et al, 2005). Acredita-se, que o parênquima das glândulas salivares de pessoas com idade mais avançada seja gradualmente substituído por tecido adiposo e fibrovascular, e que o volume dos ácinos se tornem reduzidos.

Em relação ao gênero, mulheres apresentam menores taxas de fluxo salivar comparado aos homens, provavelmente por terem glândulas salivares menores, e/ou por fatores hormonais (De Almeida et al, 2008).

Quanto ao ritmo circadiano, a taxa de fluxo salivar apresenta-se mais alta no início da manhã diminuindo progressivamente ao longo do dia, com taxas mais altas reportadas às

52 - 4 horas da manhã, e taxas mais baixas, próximo às 20h (Papacosta \& Nassis, 2011).

\section{Regulação autonômica na produção de saliva}

A secreção salivar é influenciada pelo controle neural do sistema nervoso autônomo que atua diretamente na regulação do fluxo salivar. A taxa de fluxo salivar depende primariamente do tipo do receptor autonômico que está sendo ativado.

As glândulas salivares são enervadas tanto pelos nervos colinérgicos parassimpáticos quanto pelos nervos adrenérgicos simpáticos do sistema nervoso autônomo. Apesar do controle nervoso da secreção salivar estar fortemente influenciado pela estimulação colinérgica parassimpática, a estimulação neural adrenérgica simpática também parece afetar a secreção salivar. A saliva secretada pelas glândulas sublingual e glândulas menores que produzem o muco, é regulada pela estimulação dos nervos simpáticos, enquanto a secreção salivar proveniente das parótidas e submandibulares é regulada pela inervação 
parassimpática. Apesar de saber que a secreção normal de saliva é resultado de uma ação cooperativa da inervação tanto simpática quanto parassimpática, a estimulação da inervação parassimpática é o principal estímulo para o aumento da secreção salivar (Papacosta \& Nassis, 2011).

A estimulação parassimpática induz a vasodilatação das veias que dão suprimento as glândulas salivares, resultando em um aumento considerável no fluxo sanguíneo, e consequentemente, no aumento da taxa de secreção salivar. Este aumento da taxa de secreção pode vir a alterar a composição salivar (Papacosta e Nassis, 2011).

A secreção salivar estimulada pelo sistema nervoso parassimpático é caracterizada pelo fluxo de saliva mais aquoso, com baixa quantidade de componentes orgânicos e inorgânicos. Em contraste, a estimulação simpática resulta em um baixo volume de saliva, mas rico em conteúdos orgânicos, como proteínas totais (alfa amilase) e partículas inorgânicas ( $\mathrm{Ca}^{2+}$, $\mathrm{K}^{+}$e $\mathrm{HCO}_{3}$ ) (Papacosta \& Nassis, 2011).

\section{Composição salivar}

A saliva é a primeira barreira contra a colonização de microorganismos patogênicos invasores das cavidades nasais e oral (Neyraud et al, 2012). A saliva se compõe predominantemente de água, entre 95 a 99\%, com uma densidade entre 1002 e 1012 g/L e um pH em torno de 6 a 7,4, podendo chegar até 9 após um aumento da secreção salivar (Granger et al, 2012; Papacosta \& Nassis, 2011, Farnaud et al, 2010, De Almeida et al, 2008, Schipper et al, 2007).

A composição salivar contém substâncias orgânicas e inorgânicas (Schipper et al, 2007; Dodds et al, 2005). As substâncias orgânicas são representadas pelas proteínas, glicoproteínas, enzimas (alfa-amilase, lisozima e lactoferrina), imunoglobulinas ( $\lg A, \lg M$ e $\lg G$ ), peptídeos com atividade antimicrobiana, hormônios esteroides (cortisol, testosterona e dehydroepiandrosterona, estrógenos, progesterona e aldosterona) e compostos nitrogenados (ureia, acido úrico, creatinina, lactato); a porção inorgânica contem os eletrólitos, como os cátiões: $\mathrm{Na}^{+}, \mathrm{K}^{+}$e $\mathrm{Ca}^{2+}$, e os aniões $\mathrm{Cl}^{-}$e $\mathrm{HCO}_{3}$, e os gases $\mathrm{CO}_{2}, \mathrm{O}_{2}$ e $\mathrm{N}_{2}$, que fazem da saliva um fluido hipotônico. A concentração total da maioria desses componentes mostra-se com valores bem menores na saliva quando comparada com as concentrações no soro ou no plasma; no entanto, é comprovada sua associação com os valores respectivos encontrados nas concentrações sanguíneas (Papacosta \& Nassis, 2011, De Almeida et al, 2008).

\section{Procedimentos metodológicos para a coleta salivar}

É muito importante ter atenção em todos os procedimentos para a coleta de saliva para minimizar o erro de variação entre as recolhas e/ou erros de metodologia. A ingestão de 
alimentos ou bebidas deve ser evitada por no mínimo 2 horas antes da coleta, para evitar variações na secreção salivar. Alimentos com alto conteúdo de açucares, cafeína, álcool ou acidez podem estimular o fluxo salivar ou alterar os níveis do $\mathrm{pH}$ oral, ambos podem comprometer a ligação anticorpo-antígeno e a atividade enzimática, levando a resultados inválidos nos ensaios imunoenzimáticos. Evitar escovar os dentes e mastigar chicletes ou gomas por no mínimo 1 hora antes da recolha. A amostra salivar com contaminação de sangue devido à micro-lesões orais ou abrasões da cavidade oral deve ser excluída, pois também pode comprometer os resultados (Papacosta e Nassis, 2011).

Aproximadamente dez minutos antes da coleta, os indivíduos devem lavar a cavidade oral com água destilada. O método que minimiza erros de coleta, e aumenta a fidedignidade e validade da amostra é o da salivação passiva do indivíduo. Os participantes são estimulados a imaginar sua comida favorita, e devem se sentar em uma posição confortável, com os olhos abertos, cabeça ligeiramente inclinada para frente, e evitar o movimento orofacial, para não estimular a secreção salivar. Assim que a quantidade de saliva estiver em quantidade suficiente na boca, o participante deve deixar cair o volume dentro de um frasco específico de armazenagem salivar (Granger et al, 2012).

O tempo de coleta deve ser controlado e anotado rigorosamente para, posteriormente, poder ser calculada a taxa de fluxo salivar de cada indivíduo. O fluxo salivar (mL.min-1) é determinado pela diferença da pesagem do frasco previa e posterior a recolha de saliva. A densidade da saliva assume-se como 1.0 g.mL-1. O fluxo salivar é calculado pelo quociente do volume de saliva pelo tempo de salivação passiva. As amostras devem ser coletadas no mesmo período do dia para evitar a interferência do ritmo circadiano em alguns dos componentes salivares, como na análise dos hormônios.

Após a coleta deve-se congelar a saliva o mais rápido possível, ou mantê-la em ambiente refrigerado por até 6 horas pós-coleta. Devem-se centrifugar as amostras e, congelá-las em um freezer com temperatura mínima de $-20^{\circ} \mathrm{C}$, até o momento das análises bioquímicas (Granger et al, 2012).

\section{MÉTODOS}

Para o desenvolvimento deste estudo de revisão foi realizada, inicialmente, uma busca de dados eletrônica nas bases de dados B-ON, PUBMED (MEDLINE), SCIELO, LILACS, utilizando-se os seguintes descritores em inglês/português: saliva composition (composição salivar) AND systematic review (revisão sistemática). E nessa primeira busca não houve nenhum resultado nos últimos 10 anos que contemplassem uma revisão sistemática sobre a composição salivar e todos os benefícios das análises bioquímicas possíveis de serem realizada não invasivamente. Essa lacuna científica suscitou a vontade de realizar esse estudo sistemático sobre a composição salivar. 
Resolveu-se então, eliminar a palavra "systematic" (sistemática), e na base de dados B-ON, 108 publicações apareceram; no PUBMED 8 resultados, LILACS, 4 resultados, e SCIELO não apresentou nenhum artigo de revisão com o descritor supracitado.

Assim, os artigos encontrados no presente estudo foram obtidos a partir das bases de dados B-ON, PUBMED e LILACS. Os estudos inicialmente selecionados apresentaram no título ou no resumo a palavra chave "saliva composition" (composição salivar), e na pesquisa avançada, "last 10 years" e "review", totalizando 120 estudos. A partir dessa primeira seleção, foram utilizados alguns processos de exclusão para a escrita final deste artigo. Foram excluídos (1) artigos que utilizavam amostras animais e/ou plantas (2) artigos focados em aspectos de doenças ou síndromes, (3) artigos que utilizassem qualquer tipo de intervenção (uso de alimentos ou suplementos para posterior análise da saliva), (4) artigos repetidos em diferentes bases de dados. Após o processo de exclusão, 17 artigos foram selecionados para serem lidos integralmente.

Após a leitura, identificou-se que dos 17 artigos, somente 11 inferiam no assunto específico sobre a origem e composição da saliva, métodos de recolha e processamento, e análise de biomarcadores salivares.

\section{CONCLUSÕES}

Na tabela 1 encontram-se os 11 artigos selecionados para esta revisão, autores, ano e revista de publicação.

Tabela 1. Artigos selecionados após processo de exclusão:

\begin{tabular}{|l|l|l|l|}
\hline Autor & ANO & Revista/Journal & TITULO \\
\hline Douglas A. Granger, & 2012 & $\begin{array}{l}\text { Journal Of Adoles- } \\
\text { cence 35 1081- } \\
1095\end{array}$ & $\begin{array}{l}\text { FOCUS ON METHODOLOGY: SALIVARY } \\
\text { BIOSCIENCE AND RESEARCH ON ADOLES- } \\
\text { CENCE: }\end{array}$ \\
$\begin{array}{l}\text { Christine K. Fortunato Emilie } \\
\text { K. Beltzer, }\end{array}$ & & AN INTEGRATED PERSPECTIVE \\
Marta Virag, & & \\
$\begin{array}{l}\text { Melissa A. Bright, Dorothée } \\
\text { Out }\end{array}$ & & & \\
\hline
\end{tabular}




\begin{tabular}{|c|c|c|c|}
\hline $\begin{array}{l}\text { Eric Neyraud, } \\
\text { Olivier Palicki, } \\
\text { Camille Schwartz, } \\
\text { Sophie Nicklaus, } \\
\text { Gilles Feron }\end{array}$ & 2012 & $\begin{array}{l}\text { Arquives of Oral } \\
\text { Biology 57. 556-566 }\end{array}$ & $\begin{array}{l}\text { VARIABILITY OF HUMAN SALIVA COMPOSI- } \\
\text { TION: POSSIBLE } \\
\text { RELATIONSHIPS WITH FAT PERCEPTION AND } \\
\text { LIKING }\end{array}$ \\
\hline $\begin{array}{l}\text { Elena Papacosta, } \\
\text { George P. Nassis }\end{array}$ & 2011 & $\begin{array}{l}\text { Journal Of Science } \\
\text { And Medicine In } \\
\text { Sport 14. 424-434 }\end{array}$ & $\begin{array}{l}\text { SALIVA AS A TOOL FOR MONITORING STE- } \\
\text { ROID, PEPTIDE AND IMMUNE MARKERS IN } \\
\text { SPORT AND EXERCISE SCIENCE }\end{array}$ \\
\hline $\begin{array}{l}\text { Lars Eliasson, } \\
\text { Anette Carlén }\end{array}$ & 2010 & $\begin{array}{l}\text { European Journal Of } \\
\text { Oral Sciences; } 118 \text { : } \\
435-442\end{array}$ & $\begin{array}{l}\text { AN UPDATE ON MINOR SALIVARY GLAND } \\
\text { SECRETIONS }\end{array}$ \\
\hline $\begin{array}{l}\text { T Deepa, } \\
\text { N.Thirrunavukkarasu }\end{array}$ & 2010 & $\begin{array}{l}\text { Indian Journal Of } \\
\text { Medical Sciences, } \\
\text { Vol. 64, No. 7, July }\end{array}$ & SALIVA AS A POTENTIAL DIAGNOSTIC TOOL \\
\hline $\begin{array}{l}\text { Sebastien J.C. Farnaud, } \\
\text { Ourania Kosti, } \\
\text { Stephen J. Getting, } \\
\text { Derek Renshaw }\end{array}$ & $\begin{array}{l}20 \\
10\end{array}$ & $\begin{array}{l}\text { The Scientific } \\
\text { World Journal 10, } \\
\text { 434-456 }\end{array}$ & $\begin{array}{l}\text { SALIVA: PHYSIOLOGY AND DIAGNOSTIC } \\
\text { POTENTIAL } \\
\text { IN HEALTH AND DISEASE }\end{array}$ \\
\hline $\begin{array}{l}\text { Mercedes Quintana, Olivier } \\
\text { Palicki, } \\
\text { Géraldine Lucchi, } \\
\text { Patrick Ducoroy, } \\
\text { Christophe Chambon, } \\
\text { Christian Salles, } \\
\text { Martine Morzel, }\end{array}$ & $\begin{array}{l}20 \\
09\end{array}$ & $\begin{array}{l}\text { Journal of Pro- } \\
\text { teeomics } 72.822 \\
-830\end{array}$ & $\begin{array}{l}\text { INTER-INDIVIDUAL VARIABILITY OF PROTEIN } \\
\text { PATTERNS IN SALIVA OF } \\
\text { HEALTHY ADULTS }\end{array}$ \\
\hline $\begin{array}{l}\text { Patricia Del Vigna de Al- } \\
\text { meida, } \\
\text { Ana Maria Trindade Grégio, } \\
\text { Maria Angela Naval Ma- } \\
\text { chado, } \\
\text { Antonio Adilson Soares De } \\
\text { Lima, } \\
\text { Luciana Reis Azevedo }\end{array}$ & 2008 & $\begin{array}{l}\text { The Journal Of Con- } \\
\text { temporary Dental } \\
\text { Practice, Volume 9, } \\
\text { No. 3, March } 1\end{array}$ & $\begin{array}{l}\text { SALIVA COMPOSITION AND FUNCTIONS: } \\
\text { A COMPREHENSIVE REVIEW }\end{array}$ \\
\hline $\begin{array}{l}\text { Raymond G. Schipper, Erika } \\
\text { Silletti, } \\
\text { Monique H. Vingerhoeds }\end{array}$ & $\begin{array}{l}200 \\
7\end{array}$ & $\begin{array}{l}\text { Archives of Oral } \\
\text { Biology 52. 1114- } \\
-1135\end{array}$ & $\begin{array}{l}\text { SALIVA AS RESEARCH MATERIAL: BIOCHEMI- } \\
\text { CAL, PHYSICOCHEMICAL } \\
\text { AND PRACTICAL ASPECTS }\end{array}$ \\
\hline
\end{tabular}




\begin{tabular}{|l|c|l|l|}
\hline $\begin{array}{l}\text { Johan K.M. Aps, } \\
\text { Luc C. Martens }\end{array}$ & 2005 & $\begin{array}{l}\text { Forensic Science } \\
\text { International 150. } \\
119-131\end{array}$ & $\begin{array}{l}\text { REVIEW: THE PHYSIOLOGY OF SALIVA AND } \\
\text { TRANSFER OF DRUGS INTO SALIVA }\end{array}$ \\
\hline $\begin{array}{l}\text { Michael W.J. Dodds, Dorth- } \\
\text { ea A. Johnson, }\end{array}$ & 2005 & $\begin{array}{l}\text { Journal Of Dentistry } \\
33,223-233\end{array}$ & HEALTH BENEFITS OF SALIVA: A REVIEW \\
Chih-Ko Yeh & & & \\
\hline
\end{tabular}

Após análise de todos os artigos citados, incluindo a parte anatômica das glândulas produtoras de saliva (Eliasson \& Carlén, 2010) e composição salivar (Schipper et al, 2007) conclui-se que saliva mostra-se uma ferramenta fidedigna, de fácil coleta e baixo custo para diagnosticar tanto doenças (Farnaud et al, 2010) quanto alterações agudas e crônicas de marcadores bioquímicos (Papacosta \& Nassis, 2011), proporcionadas pelo exercício.

Apesar das recolhas serem de fácil acesso, alguns detalhes devem ser levados em consideração como idade (Granger et al, 2012, Dodds et al, 2005), gênero (De Almeida et al, 2008), dieta (Neyraud et al, 2012), ritmo circadiano (Deepa e Thirrunsvukkarasu, 2010), fluxo salivar (Aps \& Martens, 2005), variabilidade interindividual (Quintana et al, 2009) e processo padrão na coleta e processamento da saliva (Papacosta \& Nassis, 2011, Granger et al, 2012); respeitando todos os processos, os resultados tendem a ser tão fidedignos quanto os obtidos na urina, soro e plasma sanguíneos (De Almeida et al, 2008).

\section{REFERÊNCIAS}

Aps J.K.M., Martens, L.C. (2005). Review: The physiology of saliva and transfer of drugs into saliva. Forensic Science International, 150. 119-131.

De Almeida, P.D.V., Grégio A.M.T., Machado M.Â.N., de Lima A.A.S., Azevedo L.R. (2008). Saliva Composition and Functions: A Comprehensive Review. J Contemp Dent Pract March; (9)3:072-080.

Deepa T., Thirrunavukkarasu N. (2010). Saliva as a potential diagnostic tool. Indian Journal Of Medical Sciences, 64 (7).

Dodds M.W.J., Johnson, D.A., Yeh, C.K. (2005). Health benefits of saliva: a review. Journal Of Dentistry 33, $223-233$.

Eliasson L., Carlén A. (2010). An update on minor salivary gland secretions. European Journal Of Oral Sciences, 118, 435-442.

Farnaud S.J.C., Kosti O., Getting S.J., Renshaw, D. (2010). Saliva: Physiology and Diagnostic Potential in Health and Disease. The Scientific World JOURNAL, 10, 434-456.

Granger, D.A.; Fortunato, C.K., Beltzer, E.K., Virag, M., Bright, M.A., Out, D. (2012). Focus on methodology: Salivary Bioscience and research on adolescence: An integrated Perspective. Journal Of Adolescence, 35, 1081-1095. 
Neyraud, E., Palicki O., Schwarts C., Nicklaus S., Feron G. (2012). Variability of human saliva composition: Possible relationships with fat perception and liking. Arquives of Oral Biology, 57, 556-566.

Papacosta, E., Nassis, G.P. (2011). Saliva as a tool for monitoring steroid, peptide and immune markers in sport and exercise science. Journal of Science and Medicine in Sport ,14, 424-434.

Quintana, M., Palicki O., Lucchi, G., Ducoroy, p., Chambon, C., Salles, C., Morzel, M. (2009). Inter-individual variability of protein patterns in saliva of healthy adults. Journal of Proteomics, 72, $822-830$.

Schipper, R.G., Silletti, E., Vingerhoeds, M.H. (2007). Saliva as research material: biochemical, physicochemical and practical aspects. Archives of Oral Biology, 52, 1114-1135. 